\section{JURNAL EKONOMI EFEKTIF}

ISSN : $2622-8882$, E-ISSN : 2622-9935

Jurnal Ekonomi Efektif, Vol. 3, No. 2, Januari 2021 @Prodi Manajemen Fakultas Ekonomi Universitas Pamulang

\title{
PENGARUH PENILAIAN KERJA TERHADAP KINERJA KARYAWAN PADA PT. JAYA MANDIRI REKABUANA DI CILANDAK
}

\author{
Devi Fitria Wilandari ${ }^{1 *}$, Denok Sunarsi², Mahnun Mas'adi ${ }^{3}$ \\ Universitas Pamulang, Tangerang Selatan, Banten, Indonesia \\ dosen02529@unpam.ac.id*
}

Manuskrip: Nov-2020; Ditinjau: Des-2020; Diterima: Des-2020; Online: Jan-2021; Diterbitkan: Jan-2021

\begin{abstract}
ABSTRAK
Penelitian ini bertujuan untuk mengetahui pengaruh penllaian kerja terhadap kinerja karyawan pada PT. Jaya Mandiri Rekabuana di Cilandak. Metode yang digunakan adalah explanatory research dengan sampel sebanyak 80 responden. Teknik analisis menggunakan analisis statistik dengan pengujian regresi, korelasi, determinasi dan uji hipotesis. Hasil penelitian ini variabel penllaian kerja diperoleh nilai rata-rata skor sebesar 3,811 dengan kriteria baik. Variabel kinerja karyawan diperoleh nilai rata-rata skor sebesar 3,911 dengan kriteria baik. Penllaian kerja berpengaruh positif dan signifikan terhadap kinerja karyawan dengan nilai persamaan regresi $\mathrm{Y}=9,701+0,326 \mathrm{X}$, dan nilai koefisien korelasi 0,649 atau memiliki tingkat hubungan yang kuat dengan nilai determinasi $42,1 \%$. Uji hipotesis diperoleh signifikansi $0,000<0,05$.
\end{abstract}

Kata Kunci: Penilaian Kerja, Kinerja Karyawan.

\begin{abstract}
This study aims to determine the effect of job research on employee performance at PT. Jaya Mandiri Rekabuana in Cilandak. The method used is explanatory research with a sample of 80 respondents. The analysis technique uses statistical analysis with regression testing, correlation, determination and hypothesis testing. The results of this study, the variable of work research, obtained an average score of 3.811 with good criteria. Employee performance variables obtained an average score of 3,911 with good criteria. Job analysis has a positive and significant effect on employee performance with the regression equation $Y=9.701+$ $0.326 X$, and the correlation coefficient value 0.649 or has a strong level of relationship with a determination value of $42.1 \%$. Hypothesis testing obtained a significance of $0.000<0.05$.
\end{abstract}

Keywords: Job Descriptions, Employee Performance. 


\section{PENDAHULUAN}

\section{A. Latar Belakang Masalah}

Manajemen sebagai suatu proses sosial, meletakkan bobotnya pada interaksi orangorang, baik orang-orang yang berada di dalam maupun di luar lembaga-lembaga formal, atau yang berada di atas maupun di bawah posisi operasional seseorang. Secara umum manajemen juga dipandang sebagai sebuah disiplin ilmu yang mengajarkan tentang proses untuk memperoleh tujuan organisasi melalui upaya bersama dengan sejumlah orang atau sumber milik organisasi. Menurut Hasibuan (2011:10), manajemen adalah ilmu dan seni mengatur proses pemanfaatan sumber daya manusia dan sumber - sumber daya lainnya secara efektif dan efisien untuk mencapai suatu tujuan tertentu.

Dalam dunia bisnis sekarang ini dituntut menciptakan kinerja karyawan yang tinggi untuk pengembangan perusahaan. Perusahaan harus mampu membangun dan meningkatkan kinerja didalam lingkungannya. Keberhasilan perusahaan dipengaruhi oleh beberapa faktor, salah satu faktor penting adalah sumber daya manusia, karena sumber daya manusia merupakan salah satu pelaku dari keseluruhan tingkat perencanaan sampai dengan evaluasi yang mampu memanfaatkan sumber daya lainnya yang dimiliki oleh organisasi atau perusahaan.

Sumber daya manusia di dalam suatu perusahaan memegang peranan sangat penting. Tenaga kerja memiliki potensi yang sangat besar untuk menjalankan aktivitas perusahaan. Potensi setiap sumber daya manusia yang ada dalam perusahaan harus dapat dimanfaatkan dengan sebaik-baiknya sehingga mampu memberikan output yang optimal. Untuk memantau kegiatan sumber daya manusia agar berjalan sesuai dengan prosedur yang diterapkan sebelumnya diperlukan suatu sistem yang berfungsi untuk mengawasi kegiatan tersebut salah satunya yaitu penilaian kerja. Penilaian kerja disini dimaksudkan untuk mengetahui sejauh mana tingkat produktivitas atau kinerja suatu individu yang ada didalam suatu perusahaan atau organisasi.

Pada umumnya orang-orang yang berkecimpung dalam manajemen sumber daya manusia sependapat bahwa penilaian kerja merupakan bagian dari seluruh proses kerja karyawan. Pentingnya penilaian kerja yang rasional dan objektif adalah untuk kepentingan karyawan itu sendiri dan kepentingan perusahaan.

Penilaian kerja adalah kegiatan manajer untuk mengevaluasi prilaku prestasi kerja pegawai serta menetapkan kebijaksanaan selanjutnya menurut Hasibuan (2012:87),sedangkan menurut Rivai (2012:66) penilaian kerja adalah proses penetapan pemahaman bersama tentang cara yang akan di capai,dan pendekatan untuk mengelola dalam waktu yang singkat ataupun lama.

Bagi karyawan penilaian tersebut berperan sebagai umpan balik tentang berbagai hal seperti kemampuan, keletihan, kekurangan dan potensinya yang pada gilirannya bermanfaat untuk menentukan tujuan,jalur, rencana dan perkembangan kariernya.

Sedangkan bagi perusahaan, hasil penilaian kerja pada karyawan sangatlah penting dan peranannya dalam pengambilan keputusan tentang berbagai hal, seperti identifikasi kebutuhan program pendidikan dan pelatihan, rekrutmen, seleksi, orientasi, penempatan, promosi, sistem imbalan dan berbagai aspek lain dari keseluruhan proses manajemen sumber daya manusia secara efektif.

Pelaksanaan penilaian kerja kerap kali diabaikan oleh para manager. Mereka beranggapan bahwa penilaian kerja cukup diserahkan kepada atasan langsung (supervisor) masing-masing karyawan dan penilaian dilakukan secara informasi saja. Argumentasi para manager tersebut biasanya karena para manager atau atasan langsung itulah yang sehari-hari membimbing dan mengawasi para bawahannya dalam pelaksanaan tugas masing-masing, para manager itu yang paling kompeten melakukan 
penilaian.

Hal inilah yang menimbulkan kelemahan-kelemahan dalam pelaksanaan penilaian pekerjaan. Gaya penilaian akan sangat beraneka ragam dengan kemungkinan interprestasi yang berbeda-beda dikarenakan kriteria yang tidak seragam, tidak ada jaminan bahwa atasanmenilai berdasarkan penilaiannya yang objektif dengan kata lain subjektif, dan hasil penilaian sangat tidak mungkin terdokumentasikan dengan baik.

Begitu juga yang terjadi pada PT. Jaya Mandiri Rekabuana yang merupakan perusahaan yang bergerak dibidang resto dan catering, dimana perusahaan ini juga menyewakan peralatan untuk kebutuhan weding, peralatan yang berhubungan dengan kuliner serta lainnya.

Sebagai perusahaan resto dan catering PT. Jaya Mandiri Rekabuana berupaya untuk mendukung semua jenis acara organaizer dengan menawarkan paket-paket kulinernya dan menu yang inovatif serta meningkatkan kualitas untuk meningkatkan kepuasan pelanggan atau klien,Perseroan menaruh perhatian khusus terhadap pengembangan Sumber Daya Manusia didalam perusahaan, sejalan dengan penambahan alat yang lebih modern, karena tanpa adanya Sumber Daya Manusia yang berkualitas, berintegritas, dan berkompeten dibidangnya maka perseroan tidak akan memperoleh hasil yang maksimal.

Manajemen Sumber Daya Manusia yang dilaksanakan oleh perseroan adalah melakukan tata kelola yang menempatkan karyawan maupun outlet cabang sebagai aset yang penting bagi perseroan. Karyawan maupun outlet cabang merupakan bagian yang tidak dapat terpisahkan dari Perseroan, sehingga tanpa keduanya maka Perseroan tidak akan dapat berjalan sebagaimana mestinya.

Dalam setiap bisnis pasti memiliki target, begitu pula dengan PT. Jaya Mandiri Rekabuana yang memiliki target setiap bulan dan akan terus bertambah setiap bulan dan tahunnya. Untuk mencapai target yang diinginkan perusahaan maka setiap dan semua orang yang bekerja dalam PT. Jaya Mandiri Rekabuana harus memiliki dedikasi, integritas, berkualitas dan berkompeten tinggi dibidangnya sehingga perusahaan akan memperoleh hasil yang maksimal.

Untuk menjaga eksistensi perusahaan tersebut karyawan selalu dituntut untuk memberikan kualitas pelayanan yang baik kepada para custamer untuk mencapai kepuasan para klien perusahaan.Sudah menjadi kewajiban dan tanggung jawab karyawan untuk memberikan yang terbaik kepada perusahaan.Oleh sebab itu karyawan dituntut untuk bekerja baik dan mengetahui secara luas tugas dan tanggung jawab sebagai karyawan bagaimana melaksanakan pekerjaan yang sudah menjadi tanggung jawab sebagai karyawan yang dituntut untuk berusaha semaksimal mungkin dalam mengambil keputusan dalam pelaksanaan pekerjaan tersebut.

Kinerja Karyawan adalah hasil dari proses pekerjaan tertentu secara berencana pada waktu dan tempat dari karyawan serta organisasi bersangkutan menurut Mangkuprawira dan Habies (2011:153). Sedangkan kinerja menurut Faustino Cardaso Gomes (2012:195) kinerja karyawan sebagai ungkapan seperti output, efisiensi serta efektifitas sering dihubungkan dengan produktivitas.

Setiap karyawan pastinya ingin selalu kinerjanya dihargai agar merasa apa yang sudah diberikan karyawan kepada perusahaan mendapat perhatian. Untuk itu, sudah seharusnya perusahaan melakukan penilaian kerja terhadap karyawannya agar mereka merasa puas atas hasil yang sudah mereka capai. Namun tidaklah mudah untuk menentukan karyawan mana yang memiliki tingkat kinerja yang baik dengan tingkat kenerja karyawan rendah. Jika tidak memiliki standsar-standar, kriteria-kriteria atau kaidah-kaidah yang akan digunakan dalam menilai. 
Selain itu juga peran para pemimpin dalam melaksanakan penilaian dituntut untuk memberikan penilaian yang objektif dan adil bagi karyawan agar terhindar dari kecemburuan yang mungkin timbul diantara para karyawannya dan keputusannya dapat diterima oleh semua pihak. Untuk melakukan semua itu diperlukan penilaian kerja yang sistematis dan mengacu pada kaidah-kaidah yang sudah ditentukan.

Berdasarkan latar belakang yang telah diuraikan tersebut maka penulis tertarik untuk menjadikan masalah tersebut kedalam penelitian dengan judul "Pengaruh Penilaian Kerja Terhadap Kinerja Karyawan Pada PT. Jaya Mandiri Rekabuana di Cilandak".

\section{B. Rumusan Masalah}

1. Bagaimana penllaian kerja pada PT. Jaya Mandiri Rekabuana di Cilandak ?.

2. Bagaimana kinerja karyawan pada PT. Jaya Mandiri Rekabuana di Cilandak ?.

3. Adakah pengaruh antara penllaian kerja terhadap kinerja karyawan pada PT. Jaya Mandiri Rekabuana di Cilandak?.

\section{Tujuan Penelitian}

1. Untuk mengetahui kondisi penllaian kerja pada PT. Jaya Mandiri Rekabuana di Cilandak.

2. Untuk mengetahui kondisi kinerja karyawan pada PT. Jaya Mandiri Rekabuana di Cilandak.

3. Untuk mengetahui pengaruh antara penllaian kerja terhadap kinerja karyawan pada PT. Jaya Mandiri Rekabuana di Cilandak.

\section{METODE PENELITIAN}

\section{Populasi}

Populasi dalam penelitian ini berjumlah 80 responden PT. Jaya Mandiri Rekabuana di Cilandak

\section{Sampel}

Teknik pengambilan sampling dalam penelitian ini adalah sampel jenuh, dimana semua anggota populasi dijadikan sebagai sampel. Dengan demikian sampel dalam penelitian ini sampel yang digunakan berjumlah 80 responden.

\section{Jenis Penelitian}

Jenis penelitian yang dipakai adalah asosiatif, dimana tujuannya adalah untuk mengetahui atau mencari keterhubungan antara variabel independen terhadap variabel dependennya

\section{Metode Analisis Data}

Dalam menganalisis data digunakan uji validitas, uji reliabilitas, analisis regresi linier sederhana, analisis koefisien korelasi, analisis koefisien determinasi dan pengujian hipotesis.

\section{HASIL PENELITIAN DAN PEMBAHASAN}

\section{Analisis Deskriptif}

Pada pengujian ini digunakan untuk mengetahui skor minimum dan maksimum skor tertinggi, ratting score dan standar deviasi dari masing-masing variabel. Adapun hasilnya sebagai berikut: 
Tabel 1. Hasil Analisis Descriptive Statistics

Descriptive Statistics

$\mathrm{N}$ Minimum Maximum Mean Std. Deviation

\begin{tabular}{ll|r|r|r|r}
\hline Sopo (X) & 80 & 28 & 44 & 34.00 & 4.016 \\
\hline Sipi (Y) & 80 & 29 & 49 & 38.11 & 4.183 \\
\hline
\end{tabular}

Valid N (listwise) 80

Penllaian kerja diperoleh varians minimum sebesar 32 dan varians maximum 48 dengan ratting score sebesar 3,811 dengan standar deviasi 4,019. Skor ini termasuk pada rentang sakala 3,40 - 4,19 dengan kriteria baik atau setuju. Kinerja karyawan diperoleh varians minimum sebesar 32 dan varians maximum 47 dengan ratting score sebesar 3,911 dengan standar deviasi 3,499. Skor ini termasuk pada rentang sakala 3,40-4,19 dengan kriteria baik atau setuju.

\section{Analisis Verifikatif.}

Pada analisis ini dimaksudkan untuk mengetahui pengaruh variabel independen terhadap variabel dependen. Adapun hasil pengujian sebagai berikut:

\section{a. Analisis Regresi Linier Sederhana}

Uji regresi ini dimaksudkan untuk mengetahui perubahan variabel dependen jika variabel independen mengalami perubahan. Adapun hasil pengujiannya sebagai berikut:

Tabel 2. Hasil Pengujian Regresi Linier Sederhana

\section{Coefficients $^{\mathrm{a}}$}

Unstandardized Coefficients Standardized Coefficients

\begin{tabular}{|c|c|c|c|c|c|}
\hline Model & $\mathrm{B}$ & Std. Error & Beta & $\mathrm{t}$ & Sig. \\
\hline 1 (Constant) & 9.701 & 2.352 & & 3.762 & .000 \\
\hline Penllaian kerja (X) & .326 & .068 & .787 & 7.809 & .000 \\
\hline
\end{tabular}

Berdasarkan hasil pengujian pada tabel di atas, diperoleh persamaan regresi Y $=9,701+0,326 \mathrm{X}$. Dari persamaan tersebut dijelaskan sebagai berikut:

1) Konstanta sebesar 9,701 diartikan jika penllaian kerja tidak ada, maka telah terdapat nilai kinerja karyawan sebesar 9,701 point.

2) Koefisien regresi penllaian kerja sebesar 0,326 , angka ini positif artinya setiap ada peningkatan penllaian kerja sebesar 0,326 point maka kinerja karyawan juga akan mengalami peningkatan sebesar 0,326 point.

\section{b. Analisis Koefisien Korelasi}

Analisis koefisien korelasi dimaksudkan untuk mengetahui tingkat kekuatan hubungan dari variabel independen terhadap variabel dependen. Adapun hasil pengujian sebagai berikut:

Tabel 3. Hasil Pengujian Koefisien Korelasi Penllaian kerja Terhadap Kinerja

Karyawan.

Correlations $^{\mathbf{b}}$

\begin{tabular}{|c|c|c|c|}
\hline & & Penllaian kerja (X1) & Kinerja Karyawan $(\mathrm{Y})$ \\
\hline \multirow{2}{*}{ Penllaian kerja $(\mathrm{X})$} & Pearson Correlation & 1 & $.649^{* *}$ \\
\hline & Sig. (2-tailed) & & .000 \\
\hline \multirow{2}{*}{ Kinerja Karyawan $(\mathrm{Y})$} & Pearson Correlation & $.649^{* *}$ & 1 \\
\hline & Sig. (2-tailed) & .000 & \\
\hline
\end{tabular}

Berdasarkan hasil pengujian diperoleh nilai korelasi sebesar 0,649 artinya penllaian kerja memiliki hubungan yang kuat terhadap kinerja karyawan. 


\section{c. Analisis Koefisien Determinasi}

Analisis koefisien determinasi dimaksudkan untuk mengetahui besarnya persentase pengaruh dari variabel independen terhadap variabel dependen. Adapun hasil pengujian sebagai berikut:

Tabel 4. Hasil Pengujian Koefisien Determinasi Penllaian kerja Terhadap Kinerja

Karyawan.

Model Summary

\begin{tabular}{lr|r|r|r} 
Model & R & R Square & Adjusted R Square & Std. Error of the Estimate \\
\hline 1 & $.649^{\mathrm{a}}$ & .421 & .414 & 2.679 \\
\hline
\end{tabular}

Berdasarkan hasil pengujian diperoleh nilai determinasi sebesar 0,421 artinya penllaian kerja memiliki kontribusi pengaruh sebesar $42,1 \%$ terhadap kinerja karyawan, sedangkan sisanya sebesar 57,9\% dipengaruhi oleh faktor lain yang tidak dilakukan penelitian.

\section{d. Uji Hipotesis}

Pengujian hipotesis dengan uji t digunakan untuk mengetahui hipotesis mana yang diterima. Rumusan hipotesis: Terdapat pengaruh yang signifikan antara penllaian kerja terhadap kinerja karyawan.

Tabel 5. Hasil Uji Hipotesis Penllaian kerja Terhadap Kinerja Karyawan.

\section{Coefficients $^{\mathrm{a}}$}

\begin{tabular}{ll|r|r|r|r|r} 
& \multicolumn{2}{c|}{ Unstandardized Coefficients } & \multicolumn{2}{|c|}{ Standardized Coefficients } & & \\
Model & \multicolumn{1}{c|}{$\mathrm{B}$} & Std. Error & \multicolumn{2}{|c|}{ Beta } & $\mathrm{t}$ & Sig. \\
\hline \multirow{2}{*}{1} & (Constant) & 9.701 & 2.352 & & 3.762 & .000 \\
\cline { 2 - 8 } & Penllaian kerja (X) & .326 & .068 & .787 & 7.809 & .000 \\
\hline
\end{tabular}

Berdasarkan hasil pengujian pada tabel di atas, diperoleh nilai t hitung $>\mathrm{t}$ tabel atau $(7,809>1,989)$, dengan demikian hipotesis yang diajukan bahwa terdapat pengaruh yang signifikan atara penllaian kerja terhadap kinerja karyawan diterima.

\section{PEMBAHASAN HASIL PENELITIAN}

\section{Kondisi Jawaban Responden Variabel Penllaian kerja}

Berdasarkan jawaban responden, variabel penllaian kerja diperoleh ratting score sebesar 3,811 berada di rentang skala 3,40-4,19 dengan kriteria baik atau setuju.

\section{Kondisi Jawaban Responden Variabel Kinerja Karyawan}

Berdasarkan jawaban responden, variabel kinerja karyawan diperoleh ratting score sebesar 3,911 berada di rentang skala 3,40 - 4,19 dengan kriteria baik atau setuju.

\section{Pengaruh Penilaian kerja Terhadap Kinerja Karyawan}

Penllaian kerja berpengaruh signifikan terhadap kinerja karyawan dengan persamaan regresi $\mathrm{Y}=9,701+0,326 \mathrm{X}$, nilai korelasi sebesar 0,649 atau memiliki hubungan yang kuat dengan kontribusi pengaruh sebesar $42,1 \%$. Pengujian hipotesis diperoleh nilai t hitung $>\mathrm{t}$ tabel atau $(7,809>1,989)$. Dengan demikian hipotesis yang diajukan bahwa terdapat berpengaruh signifikan antara penllaian kerja terhadap kinerja karyawan diterima.

\section{PENUTUP}

\section{Kesimpulan}

a. Variabel penllaian kerja diperoleh ratting score sebesar 3,811 berada di rentang skala 3,40 - 4,19 dengan kriteria baik atau setuju.

b. Variabel kinerja karyawan diperoleh ratting score sebesar 3,911 berada di rentang 
skala 3,40 - 4,19 dengan kriteria baik atau setuju.

c. Penllaian kerja berpengaruh signifikan terhadap kinerja karyawan dengan persamaan regresi $\mathrm{Y}=9,701+0,326 \mathrm{X}$, nilai korelasi sebesar 0,649 atau kuat dan kontribusi pengaruh sebesar $42,1 \%$ sedangkan sisanya sebesar $57,9 \%$ dipengaruhi faktor lain. Uji hipotesis diperoleh nilai t hitung $>\mathrm{t}$ tabel atau $(7,809>1,989)$.

\section{Saran}

a. Perusahaan harus menegakkan peraturan dengan baik sesuai dengan ketentuan yang berlaku guna menjamin karyawan diperlakukan dengan adil.

b. Perusahaan harus selalu memberikan semangat dan apresiasi yang layak untuk memastikan karyawan memiliki semangat kerja yang tinggi.

c. Kinerja perusahaan dapat ditingkatkan dengan memberdayakan karyawan dengan menegakkan peraturan yang baik dan pemberian motivasi yang lebih inten lagi.

\section{DAFTAR PUSTAKA}

Abdullah, M (2014) Manajemen dan Evaluasi Kinerja Karyawan, Yogyakarta: Penerbit Aswaja Pressindo.

Akbar, I. R. (2020). Pengaruh Kompensasi Dan Etos Kerja Terhadap Komitmen Organisasi Pada Pt. Central Buana Mandiri. Value: Jurnal Manajemen dan Akuntansi, 15(1), 73-80

Algifari. (2015). “Analisis Regresi untuk Bisnis dan Ekonomi”. Yogyakarta: BPFE.

Arikunto, Suharsimi (2014). "Prosedur Penelitian Suatu Pendekatan Praktek". Jakarta: Rineka Cipta.

Bangun, Wilson. 2012. "Manajemen Sumber Daya Manusia”. Jakarta: Erlangga

Bejo Siswanto (2013) Manajemen Tenaga Kerja Rancangan dalam Pendayagunaan dan Pengembangan Unsur Tenaga Kerja”, Bandung: Sinar Baru.

Edi Sutrisno (2016). Manajemen Sumber Daya Manusia. Jakarta: Prenadamedia Group.

George Terry R \& Rue, Leslie W. Rue (2016) Dasar-Dasar Manajemen, Jakarta Bumi Aksara.

Gerry Dessler (2016) Human Resources Management, Prenticehall, London: International Inc.

Handoko (2016) Manajemen Personalia dan Sumberdaya Manusia. Yogyakarta: BPFE.

Handoko T. Hani, (2012), Manajemen Personalia dan Sumber Daya Manusia, edisi kedua, BPFE, Yogyakarta

Hasibuan, Malayu S.P. (2016). Manajemen Sumber Daya Manusia. Edisi Revisi. Jakarta: PT Bumi Aksara.

Hermanto Suaib, Joelman Subaidi, Muhammad Hatta, Sufirman Rahman, Ahmad Khoiri, (2020) Criminal Act of Drugs Abuse as Extraordinary Crime in Indonesia, International Journal of Psychosocial Rehabilitation 24 (8): 2631-2643, Doi:10.37200/IJPR/V24I8/PR280282

Imam Ghozali (2017). "Aplikasi Analisis Multivariate Dengan Program SPSS”. Edisi Kelima. Semarang: Badan Penerbit Undip.

Istijanto (2014) "Riset Sumber Daya Manusia". Jakarta: PT. Gramedia Pustaka

Jasmani, J., \& Sunarsi, D. (2020). The Influence of Product Mix, Promotion Mix and Brand Image on Consumer Purchasing Decisions of Sari Roti Products in South Tangerang. PINISI Discretion Review, 1(1), 165-174.

Kharis, Ismu Fadli (2011). "Studi Mengenai Impulse Buying dalam Penjualan Luthans Fred (2014) Organizational Behavior, Ney York: McGraw-Hill, New York. Mangkunegara, Prabu Anwar. (2016). Evaluasi Kinerja SDM. Cetakan ke tujuh, PT Refika 
Aditama: Bandung.

Muis, I., Nurdin, I., Erlangga, H., \& Engkus, E. (2019). Post Disaster Social Vulnerability: Policy Analysis and Implementation in Communities in Indonesia. Journal of Critical Reviews, 6(5), 59-66.

Robbins, P.S, \& Judge, A.T. (2003). Organizational Behavior. Jakarta: Salemba Empat.

Santoso, Singgih (2015). "Menguasai Statistik Multivariat". Jakarta: PT Elex Media Komputindo.

Sarwani, S., Akbar, I. R., Handoko, A. L., \& Ilham, D. (2020). Pengaruh Pelatihan dan Motivasi terhadap Produktivitas Kerja Karyawan pada PT. Lion Mentari Airlines Bandara Internasional Soekarno Hatta Cengkareng. Jurnal Ilmu Komputer dan Bisnis, 11(2a), 91-100.

Sedarmayanti (2016) Manajemen Sumber Daya Manusia, Reformasi Birokrasi dan Manajemen Karyawan Negeri Sipil, Cetakan Kelima, Bandung: PT Refika Aditama.

Sofyan, S., Prasada, D., \& Akbar, I. R. (2020). Pengaruh Motivasi, Lingkungan Kerja dan

Kepuasan Kerja Terhadap Kinerja Guru SMP/MTs Muhammadiyah Cabang Sawangan. Jurnal Ilmu Komputer dan Bisnis, Volume 11, Issue 2a, Pages 44-55

Sudjana (2014) "Metode Statistika", Bandung: Tarsido.

Sugiyono (2017), "Metode Penelitian Administrasi : dilengkapi dengan Metode R \& D". Bandung: Alfabeta.

Suhartanto (2014). "Metode Riset Pemasaran". Bandung: Alfabeta

Sunarsi, D., Akbar, I. R., Prasada, D., Kristianti, L. S., Muliani, H. S., Anjayani, N. S., \& Hendra, H. (2020). Pengaruh Kompetensi dan Pengembangan Karir terhadap Kinerja Karyawan pada PT. Berkah Cemerlang di Jakarta. Jurnal Ilmu Komputer dan Bisnis, 11(2), 2465-2472.

Veithzal Rivai (2015) Manajemen Sumber Daya Manusia Untuk Perusahaan, Jakarta: Raja Grafindo Persada.

Wibowo (2015) Manajemen Kinerja, Jakarta: PT. Raja Grafindo Persada. 